\title{
Using Aristotle's theory of friendship to classify online friendships: a critical counterview
}

\author{
Sofia Kaliarnta ${ }^{1}$
}

Published online: 22 January 2016

(c) The Author(s) 2016. This article is published with open access at Springerlink.com

\begin{abstract}
In a special issue of "Ethics and Information Technology" (September 2012), various philosophers have discussed the notion of online friendship. The preferred framework of analysis was Aristotle's theory of friendship: it was argued that online friendships face many obstacles that hinder them from ever reaching the highest form of Aristotelian friendship. In this article I aim to offer a different perspective by critically analyzing the arguments these philosophers use against online friendship. I begin by isolating the most common arguments these philosophers use against online friendship and proceed to debunk them one by one by pointing out inconsistencies and fallacies in their arguments and, where needed, offering empirical findings from media and communication studies that offer a more nuanced view on online friendships. I conclude my analysis by questioning the correctness of the application of the Aristotelian theory of friendship by the critics of online friendship: in my view, the critics are applying the Aristotelian theory to online friendships in a rather narrow and limited way. Finally, I conclude my thesis by proposing that in the rapidly changing online landscape, a one-size-fits-all application of the Aristotelian theory on friendship is not sufficient to accurately judge the multitude of relationships that can exist online and that the various positive and valuable elements of online friendships should also be acknowledged and analyzed.
\end{abstract}

Sofia Kaliarnta

sofia.kaliarnta@gmail.com; S.Kaliarnta@tudelft.nl

1 Philosophy Department, Faculty of Technology, Policy and Management, Delft University of Technology, Jaffalaan 5, 2628 BX Delft, The Netherlands
Keywords Virtue ethics - Aristotle · Online friendship · Social networking sites · Internet · Virtual friendship · Social media $\cdot$ Friendship

\section{Introduction}

The rise of the Internet and other online communication technologies has assisted the proliferation of connecting and creating relationships with people online. Various philosophers consider these friendships as a poor substitution of friendships in real life. In September 2012, a special issue of the journal Ethics and Information Technology was devoted to online friendship. Many of the philosophers who contributed in the special issue analyzed online friendship by using Aristotle's theory of friendship. They concluded that online friendship cannot reach the highest level of friendship according to the Aristotelian model. With this article, I aim to highlight some problematic aspects of the arguments used by the philosophers who are viewing online friendships as less valuable. I will do so by first presenting the main points of the critics of online friendship as they were laid down in the special issue; I will then offer my counterpoints and objections against the arguments used by the critics of online friendship. In "Using the Aristotelian theory of the good life to analyze online friendships" section I give a short overview of Aristotle's theory on friendship and I subsequently present the main points of the critics of online friendship. The main point of departure in their analysis is the application of the Aristotelian theory on friendship. The most common conclusion is that despite several positive aspects, friendships that exist purely online cannot achieve the highest level of Aristotelian friendship. I go on in "Identity construction online and multiple communication filters: 
arguments and counterarguments, Loss of the 'shared life' between online friends: arguments and counterarguments and 'Settling' for less valuable forms of friendship online: arguments and counterarguments" sections to counteract the previously presented arguments against online friendship; my point-by-point analysis concludes on "Questioning the application of the Aristotelian framework on online friendships" section with questioning the correctness of the application of the Aristotelian theory of friendship by the critics of online friendship. In my view, the critics are applying the Aristotelian theory of friendship to online friendships in a rather narrow and limited way. In this way, the possible positive elements of online friendships are deemed as less significant than offline friendships. Finally, I conclude my thesis by proposing the following: the online landscape is rapidly changing, and it includes various communication mediums and platforms with differing aims and scopes. In such a landscape, a one-size-fits-all application of the Aristotelian theory on friendship is not sufficient to accurately judge the multitude of often deep and meaningful personal relationships that can exist online. It is thus necessary that the various positive and valuable elements of online friendships are also acknowledged and analyzed.

\section{Using the Aristotelian theory of the good life to analyze online friendships}

Aristotle's theory of the good life and in particular, his analysis of the role that friendships play in achieving human flourishing, has been one of the most influential and long-lasting theories on human connections and friendships. Aristotle considers philia (friendship) as an essential component of 'the good life': in friendship, friends love "the lovable, and this is good, pleasant, or useful" [NE VIII.2: $1155 \mathrm{~b}, 19] .{ }^{1}$ Friends are defined as people who "must be mutually recognized as bearing goodwill and wishing well to each other" [NE VIII.2: 1156a, 4-5]. Friendships of utility are based on certain advantages or goods that one can attain from one's friend; for example, having a friend who has professional connections that we can profit from, or a friend who lavishes us with expensive gifts. Friendships of pleasure are friendships where the main motivation for continuing the friendship is the pleasure we get from our friend's company; for example, a friendship where two friends share a love of history books or enjoy playing chess together. The third kind of friendship, virtue friendship, is based on mutual admiration of our friend's character and sharing of the same values.

\footnotetext{
1 Translations of Aristotle's text taken from Ross, W.D. (2009) Nicomachean ethics.
}

Aristotle considers virtue friendship as the highest form of friendship between two people; unlike the first two kinds of friendships which are more based on self-interest, virtue friendship is based on 'mutual concern of each person for the other for his own sake' (Bowden 1997, p. 65). It is considered to be the most durable kind of friendship, since it is not affected by external and instrumental factors. For example, we might lose interest in our friend if he stops buying us expensive gifts, or the intensity of the friendship with our chess-playing friend might lessen if he becomes much more interested in solving puzzle words rather than playing chess with us. However, a virtuous friend loves us for our character and belief in similar moral values.

In recent years, friendships between individuals do not only take place in the usual venues of everyday life, but have increasingly begun to be formed online. People can meet each other on the Internet in various ways: through social networking sites such as Facebook, through online games such as World of Warcraft or through online communities. Often, the interaction between two individuals online can become frequent and intense, with exchange of very personal details and stories, as well as a heightened sense of connection and understanding (Henderson and Gilding 2004).

However, the moral value of such friendships has been called into question by some philosophers; they seem to doubt whether a friendship sustained exclusively over the Internet, with no real life interaction could be still classified as 'real' friendship and reach the level of virtue friendship, i.e. the highest level of friendship according to the Aristotelian theory. While it is mostly agreed that online friendships can possibly reach the level of utility or pleasure friendship, several philosophers argue that a true virtue friendship cannot be reached purely online. This has been argued by various scholars in the special issue of the journal Ethics and Information Technology on online friendship (September 2012). The Aristotelian theory of friendship is the preferred tool with which these scholars compare and contrast online friendships with real-life, offline ones. While these philosophers do recognize that certain benefits can be derived from online friendship, they nevertheless conclude that those benefits are of an instrumental nature; they pertain much more to the lower types of Aristotelian friendship such as utility and pleasure friendships. According to their application of the Aristotelian theory, virtue friendship, the highest form of friendship, is indeed viewed as impossible to achieve online, due to the following three reasons: (1) selected presentation of oneself online which can prevent us from truly knowing our friend's character, (2) the multiple filters in communication online that can lead to distortion and loss of important clues, as well as the inability to engage in many different activities with our online friend, (3) 
skepticism regarding the way that the Internet and especially social networking sites tend to shape how we interact and relate to one another. It is considered troubling that young people in particular might be satisfied with the kind of fast-paced and shortened contact that is characteristic of social networking sites. Such a development is thought to lead young people away from developing friendships that correspond with the Aristotelian ideal. This could mean that young people could be missing out on the possibility of becoming fully-developed virtuous individuals.

I do agree that by the very nature and characteristics of the Internet as a communication medium, friendships created and maintained online have their own special set of challenges and downsides. I understand that such challenges could potentially impede the full development of a meaningful friendship online. However, the critics are decrying the possibility of a higher level of friendship existing online by using offline friendships as the 'natural' way of things. My own analysis of their arguments aims to highlight certain inconsistencies and fallacies. I also maintain that broad generalizations about online friendship do not necessarily apply for all the vast array of communication platforms online (social networking sites, online games, online communities etc.); each communication platform offers and allows different modes of communication and interaction between users. Below, I will first present and then counter-analyze the arguments offered previously against online friendship.

\section{Identity construction online and multiple communication filters: arguments and counterarguments}

One of the biggest points of contention for philosophers regarding online friendships is the possibility that persons online might (either intentionally or unintentionally) be less forthcoming with revealing their character, thoughts and beliefs in their entirety. In their view, people online may choose to reveal the aspects of themselves that they consider most positive (thus hiding away less positive traits and ideas). Another possibility is that, even if a person online truly believes that he is totally honest and open about presenting himself in a way that reveals his true self to others, that this might actually not be the case, due to the many filters of communication online. For example, McFall (2012) describes two different types of communication filters that pervade our communication with others: there is multi-filtered communication and single-filtered communication. In multi-filtered communication, person $\mathrm{A}$ relays information to person $\mathrm{B}$ after having filtered the events through her own interpretation (which could mean that the way the information is relayed can be factually incorrect). Single filtered communication occurs when person $\mathrm{B}$ has direct access to person A's experiences (perhaps because person B and person A were physically together when an experience occurred); thus, the information passes no (potentially obscuring) filter. McFall then goes on to explain the importance of single-filtered communication in truly getting to know our friend's character and moral value. His conclusion is that single-filtered communication is difficult to achieve with the available technological tools online. So, by the very nature of online interactions, friendships of virtue cannot be achieved online.

This view is also shared by Cocking et al. (2012), who note that the many limitations and barriers inherent to online interaction can be a hindrance in really getting to know the character of our online companion. They make the argument that "what is prone to be missed or distorted are various aspects of ourselves about which we do not approve, or we think are not notable or we simply do not notice" (p. 181). Cocking et al. also express concerns about the increasing prevalence of friendship online among teenagers and young people. They make the remark that the Internet gives people the opportunity to construct their image as they see fit (e.g. perhaps by portraying themselves in a very positive light). This unprecedented control of presenting oneself can be very appealing to young people, who are in the process of constructing their own identity. This feature can also give young people the idea that not only can they carefully create their (public) image and identity 'in their own terms', but that they can also begin to "think about these connections to others solely in terms of their choices and control." (p. 183). This development is in discordance with the Aristotelian ideal of the perfect friendship, where the moral development of both friends is informed by their mutual understanding and appreciation of the other person's virtues. Additionally, Cocking et al. note that especially for young people who use social networking sites, it is particularly attractive to highlight their best aspects and embellish their interests while obscuring their less positive sides. Young people are already in a stage where they explore their own identity and the ways they can relate to others, and Cocking et al. claim that by using social networking sites, they can create a very idealized and highly fine-tuned version of themselves.

However, what regularly happens in social networking sites is that social network users have people in their network who they also know offline. Having people present on your circle of friends on Facebook, whom you also know offline, can limit or mitigate the identity construction effect. It is quite possible that offline friends will recognize an attempt of their friend to create a more positive, or altogether different, image than what she really is and bring the matter to her attention. Let's take the example of a young 
teenage girl who decides to present a more refined image on Facebook by claiming she is very fond of Jane Austen novels. Such a claim would not go unnoticed by her offline friends, who know that she actually has never read any of the works of Jane Austen. They could make public comments wondering when exactly she has started reading Jane Austen books; in this way, they could bring to everybody's attention that their friend's claim is in fact false.

This particular characteristic of social media is also important when it comes to analyzing the way teenagers use social media. Often the profile information they provide is wildly inaccurate, like stating that they live in Ulan Bator, Mongolia, when they actually live in Boston, USA. This is, however, a way for them to inject humor and wit into their online self-presentation and represents no actual effort of presenting a whole new image. Boyd, in her book "It's complicated: the social lives on networked teens" (2014), has conducted an eight-year-long ethnographic research on teenagers' internet and social media use in the United States. She mentions the example of 16-year-old Michael, who sees no reason to put up accurate information on his social media profile, since "all my [social media] friends are actually my friends; they'll know if I'm joking around or not" (p. 46). Boyd goes to note that most teenagers "aren't enacting an imagined identity in a virtual world. Instead, they're simply refusing to play by the rules of self-presentation as defined by these sites. They see no reason to provide accurate information, in part because they know that most people who are reading what they post already know who they are. [...] Teens don't see social media as a virtual space in which they must choose to be themselves or create an alternate ego. They see social media as a place to gather with friends while balancing privacy and safety with humor and image." (pp. 46-47). It seems thus that teenagers have found ways to navigate through the (implicit or explicit) rules and behavioral expectations of social media and are appropriating them as a tool for connection and exploration.

Especially nowadays, connecting to others online offers more points of reference and ways in which individuals can obtain information about their online friend. This holds true not only for those friendship which exist both online and offline, but also for the so-called 'purely' online friendships. For example, on Facebook it is common for users to create profiles using their real name and photograph. If one makes a friend on Facebook, he can use this information in order to find out more about their new connection, i.e. by looking up their name on an online search engine. This can reveal more relevant information, such as a personal website, a LinkedIn or Twitter profile or a Skype account. This means that more aspects of a person's life are available online: their professional career, their love of camping or even their political preferences. In this way, the previous division between purely online and offline friendships seems to fade, since in the past, we often had zero access to our online friend's life and beliefs and had to rely exclusively on the information they provided us. Nowadays, the great amount of information that we can find about our online friends can assist in minimizing the effects of selective self-presentation.

It can even be argued that social media and their use can have positive effects towards minimizing the knowledge problem as presented by Cocking et al. (2012). For example, Elder (2014) makes a good point about how the multitude of information about persons online can actually help, rather than hinder, our overall assessment of them: "online, conversations leave digital "paper trails", making it easier to cross-check stories and consider a person's comments in light of the overall picture of their character presented by their online presence. For example, the person who expresses one view on social issues to you, but whose Facebook wall is full of posts and memes to the contrary, gives grounds for an overall assessment of character which takes the totality of evidence into consideration" (p. 292). A similar point about the possible trustworthiness of online acquaintances is made by Turilli et al. (2010); they opine that "online identity can be diachronic and the history of the performances associated with that specific online identity can be recorded and made available. In this way it is possible to establish the reputation of an online identity without the need to also associate such a reputation to a specific physical individual." (p. 338) One can thus make the point that in this way, our online presence can be consistent and reliable: our online friends can see the many aspects of our personality and how these evolve through time.

Returning to social media, the "mutual friends" function of Facebook can be used as an informal "reference" for those who wish to make online friends with people they don't know, but wish to have an extra measure of reliability. Let's assume you receive an invitation to connect on Facebook from "Peter". You notice that "Peter", whom you don't know offline, is also Facebook friends with your offline friend "John". If you wonder whether you should add Peter to your Facebook friends' list, you could ask John to give you more information about him. Since John knows Peter in real life, this can become a "stamp of approval"; Peter can be trusted, even though you have never met him personally. This is the online equivalent of meeting someone through mutual friends: you find it easier to trust them precisely because of your mutual friends, who have the informal function of "quality assurance". If you are friends with someone, you usually know their positive traits and ergo, their other friends can be viewed in an equally positive way. 
Precisely because of the proliferation of social media, it has become more commonplace to quickly exchange e-mail addresses, or send Facebook or LinkedIn invitations to connect with people we have just met offline. Quite often, we only know this new person in a superficial way and we have not had the time to get to know them in depth. For example, information about marital status, political and religious beliefs, studies and other interests are often not mentioned during the first stages of getting to know someone offline. Yet, through social media, it becomes easier to have more information about our offline acquaintances, and thus, we can obtain a more "complete" idea of who they are at the click of a button; their two sisters and one brother, their love for Joy Division, their exchange semester in Dublin during their Master's studies, or their Ph.D. degree from Boston University-all these information are at our disposal. Who you are (or present yourself to be) online can have direct consequences for your offline life. This could help in the "screening" process, if we for example have met a new acquaintance at our painting group: he is pleasant and funny and we look forward to get to know him better. If however, once we add him on Facebook, we see that his wall is filled with sexist and homophobic posts, and he seems to be unapologetic about it, this might make us reconsider the option of deepening our relationship with him. In fact, it is possible that what we reveal in our online profiles can actually be used to find information that we have carefully hidden in our offline lives. This is becoming common practice for many who are dating. Often, their search in the social media profiles of their date provides them with an unpleasant surprise, such as finding out that the person they are dating is already in a relationship, as it happened to a 22-year old woman in the $\mathrm{UK}^{2}$ So one could potentially argue that while it is indeed an issue that our online presence could have distorting effects on our offline lives, in some cases it is actually possible that our online presence is revealing information that could correct our distorted offline presentation.

It is true that the phenomenon of refining of the self, (including selective presentation of only our best points, or a construction of a different identity altogether) still can and does happen online; especially in environments where one is completely anonymous, such as chat-rooms. However, it is clear that we are moving away from the era of nicknames and avatars and the sort of "pseydonimity" they awarded, and towards a digital environment where all kinds of information about us are readily available. These information can offer a far more wholesome picture of our preferences, likes, dislikes and beliefs. Especially in social

\footnotetext{
2 http://www.manchestereveningnews.co.uk/news/greater-manche ster-news/facebook-pippa-mckinney-post-girlfriend-10199577.
}

networking sites, the presence of offline friends and their comments or reactions can rectify the possible voluntary distortion of presenting oneself. These new developments in the online landscape present us with new opportunities. The information we can get from social media can be used to counteract the previous lack of knowledge about our online relationships.

Similarly to the points made by Cocking et al. (2012), Fröding and Peterson (2012) argue that the technological features available in online communication make it very easy for online users to have a great amount of control regarding the time, frequency and duration of interactions. To them, this is a problematic point because, "they [the users] can (even unintentionally) choose to communicate only in certain situations. The price they pay is that they miss out on important, potentially problematic and complex, aspects of the friends' personality. Therefore the agent ends up admiring and loving parts of the friend rather than the whole of her." (p. 205). When it comes to the issue of distorted self-presentation online, they provide a constructed example of two online friends, Alice and Betty. Alice and Betty have been interacting online for a long time and they have created a close bond. Alice would like to meet Betty in real life as well, but Betty is vague and dismissive, which hurts Alice's feelings. When Alice goes to the local swimming pool, she happens to see Betty there as well, recognizing her from photographs they have shared. Betty is doing physiotherapy with the help of a trainer, since she has been involved in an accident and thus is now physically disabled. Alice was not aware of this fact, since Betty, not wanting to be viewed by her friend as 'different', chose to not disclose this fact. Fröding and Peterson conclude that the friendship between Alice and Betty cannot be a true friendship of virtue, since "complete and excellent friendship can only obtain when both agents are fine, noble and excellent in every aspect, and this is incompatible with the withholding or manipulation of relevant information" (p. 205). By using this example, Peterson and Fröding reach the conclusion that by not knowing this important fact about her friend Betty, Alice did not have all the necessary information needed in order to make a correct evaluation of her friend; her judgment of Betty's character was thus ill-founded. Alice's admiration and care for Betty were not based on the truth, hence, their friendship cannot attain the highest Aristotelian level.

However, one could wonder whether knowing that your online friend is disabled or not has any bearing on their moral character - why finding out that your online friend is disabled should mean that the friendship has lost part of its moral significance? While one could stress the importance of honesty, especially in a relationship between friends, it is a fact that in everyday life, many factors about ourselves could affect the way others think about us. Our profession, 
our sex, our race, our formal education (or lack thereof), our possible disability are all factors that can define our identity and more importantly, the way others perceive us and relate to us. This aspect of human behavior is rather pervasive and it explains the huge appeal the Internet offers: online you are not defined by your appearance, your financial situation or your illness. Your contribution to discussions and interactions online is judged on merit-a surgeon can be on equal footing with a janitor. As McKenna et al. (2002) observe, "there are aspects of the Internet that enable partners to get past the usual obstacles or 'gates' that in traditional interaction settings often prevent potentially rewarding relationships from getting off the ground" (p. 10).

Regarding people with disability, who might experience people treating them differently in real life (perhaps they feel people pity them or that they are too quick to agree with them in order to not hurt their feelings), the Internet offers them the opportunity to socialize and express themselves without being defined by their handicap, ethnicity or social status. Coming back to the example of Alice and Betty, Bülow and Felix (2014) offer an interesting point of view: in the offline world, Alice and Betty are not on equal footing. Unlike Alice, who has freedom of movement and has thus many opportunities to socialize and make friends, Betty's physical impairment makes it difficult for her to visit restaurants, cinema's etc. and meet new people. Added to this is Betty's own embarrassment about her handicap. However, " Betty is not hindered by her impairment when she is interacting online; here, her morally good character shines through. This allows her to communicate more openly and wholeheartedly than is possible when she is interacting physically. Her communication and interaction online can go pass prejudices or assumptions about her impairment. [...] Online Betty may come to foster her moral character in her interaction with Alice-only here can they mirror each other on an equal footing." (p. 12) In other words, the Internet becomes a "leveling field" factor; it enables people who would be unequals offline to be able to interact in equal terms with each other online.

This aspect of the Internet, I dare claim, is actually a positive one, since it gives people coming from less privileged positions the chance to participate equally in the online world and create connections based not on aspects of themselves they have no control about, but on the strength of their personality and character. Suler (2004) makes the point that, "the traditional Internet philosophy holds that everyone is an equal, that the purpose of the net is to share ideas and resources among peers. [...] Even if people do know something about an authority figure's offline status and power, that elevated position may have less of an effect on the person's online presence and influence. In many environments on the Internet, everyone has an equal opportunity to voice him or herself." (p. 324) Similarly, research conducted by Chan and Cheng (2004) on the quality of online versus offline friendships, concluded that online friendships between men and women were considered to have a higher quality than offline friendships. It can be argued that the physical distance between the two friends helps mitigate specific issues that might arise from offline crosssex relationships, such as unwanted sexual attraction. In other words, the Internet could have a positive influence in friendship development between the sexes. Chang and Chen's research also covers the development and the proliferation of online cross-cultural friendships. The results show that the typical cultural differences and misunderstandings present in offline settings are actually less pronounced online, making online cross-cultural friendships easier to develop. One could thus make the tentative point that the Internet, precisely because of the built-in limitations of distance and lack of physical features can foster valuable relationships of equals between people who would not as easily been able to become friends offline.

Briggle (2008) makes an interesting point regarding the contrast of offline and online friendships. He claims that offline friendships too can be constrictive and limiting in their capability to allow us to fully express our self, our personality and motivations to another person. As he notes,

offline friendships occur within complex webs of relations and social structures. These webs are freighted with demands of status, norms, expectations, and conventions that shape the nature of friendships. Friends are more or less consciously squeezed into various compromises by the structure of this overarching social ecology. It can be hard, then, to really "be myself" within any space that this web affords. There may be a secret or deeper self that is unable to emerge as we must enact in our daily lives (p. 74)

He uses the example of an accountant who does not feel really comfortable in any of her life-environments; underlying currents and expectations, past events and attitudes create boundaries for her self-expression: she cannot truly "be herself" at her work environment and neither is that possible in her volleyball team and in her poetry club. Such embedded distortions being at play in offline relationships can be offset by the distance of online relationships, where, precisely because there is no pre-existing web of relationships and social obligations, an individual can feel free to openly express aspects of themselves that they "file away" in their offline lives and thus pursue relationships of depth and candid exchange. 
The point that Briggle makes is a point worth pondering: many of the arguments used to explain why certain aspects of online friendships are problematic could also be said for offline friendships. Even with our closest offline friends, there are times when we choose not to share certain information about ourselves, either because we feel they do not need to know or because perhaps we are afraid of their judgment. Also, quite often, friends made in different environments get to see different aspect of our personhood, or as Cocking (2008) writes, they see these "plural aspects of self" (p. 127), but not a completed whole: friends from work might know us as serious and calm, while friends from our student years might know us as daring and with a peculiar sense of humor.

In fact, the internet might allow us with more possibilities to express our "true selves". In research conducted by McKenna et al. (2002), it was discovered that individuals who suffer from social anxiety, shyness or a lack of social skills, reported that they felt that they could express their "true" selves better online, and as a result, were able to form close and meaningful relationships with people they met online. Similar results about the better expression of our "true self" online were also reported by Bargh et al. (2002). McKenna, Green and Gleason also measured the durability of these relationships by contacting the survey respondents 2 years after the initial data collection and asked them about the present status of their previously reported online friendships and relationships: the majority of those relationships were found to be still intact 2 years later. It is thus conceivable to argue that precisely due to the absence of common "gating" features that could otherwise halt the development of a relationship offline, the Internet offers individuals the possibility to express their true selves in a more wholesome way and so, they are able to create lasting relationships which may otherwise be impossible to obtain.

\section{Loss of the 'shared life' between online friends: arguments and counterarguments}

Another concern arises from the apparent absence of 'a shared life' between online friends. For Aristotle, sharing the same experiences, in number, kind and diversity, is an essential component for people who are friends of virtue, in order to further develop morally. This is shared by McFall (2012), who claims that friendships of virtue cannot flourish online, since character friends (as he refers to friends of virtue) need to live together. He argues that virtue friendships cannot be created and sustained entirely through technological meditation because of the lack of shared activities with our friend that would help us in truly getting to know their character and thus, to share our moral development. He quotes Aristotle in the kind of activities character friends share together: drinking, playing dice, practicing a sport or studying philosophy together-by sharing these activities, moral development between friends can occur. Although McFall does acknowledge that many of the activities Aristotle mentions can now be shared online, he maintains that even so, these online friendships with shared activities can only be utility or pleasure friendships, since "one thing that characterfriends provide for each other, an opportunity for robust moral reflection and improvement of the self and other, cannot be transferred as easily through technological means" (p. 222). Fröding and Peterson (2012) subscribe to this view as well, by claiming that friendships of virtue cannot be sustained exclusively online and even the most intense kind of online relationship must always be paired with significant interaction offline. According to their analysis of the Aristotelian theory of the good life, a shared life between friends is superior and it is far better for the quality of the friendship if the two friends partake together in a plethora of activities. As they note, "two persons that spend time together in real life are more likely to face a wider spectrum of different situations, and consequently, encounter a larger range of topics meriting contemplation. [...]. In real life we stumble on situations that are both novel and unexpected and we have to deal with them in promptu. This seldom happens on the internet." (p. 204). Sharp (2012) similarly stresses the importance of prolonged offline contact between friends as a robust way to truly become familiar with our friend's character, while stressing that "we must be able to perceive the other person in a full, rich way, and he or she must be able to perceive us as well. This creates the necessary bond, one that will allow the fullest communication of feelings and goals, with the least ability to fool the other person or hide our vices." (p. 239). Without actively sharing our lives, our sorrows and moments of triumph, our beliefs and weaknesses with our friend, our friendship cannot reach the highest Aristotelian level of friendship.

However, in a case study, Munn (2012) presents the possibility of friendship in the immersive virtual worlds of Massively Multiplayer Online Role-Playing Games (MMORPGs), with the very popular online game World of Warcraft used as the prime example. Munn makes the case that such online games provide ample opportunities for players to participate together in the same activity (e.g. grouping together to fight against an enemy group or retrieving a valuable amulet). During those shared activities together, people have the possibility to communicate and coordinate their actions via various channels, whether these are internal channels provided by the game, or external channels, organized by the players themselves (e.g. through external webpages where the players can 
communicate or by using Ventrilo, a voice-over internet program for communication of large groups online). By grouping together and sharing the same activity of pursuing a common goal,

those in the group demonstrate their character, their roles and desires, and it becomes apparent to the other members of the group whether or not the prerequisites for friendship are present. [...] Similarly, over an extended period of participation in this shared virtual activity, the group will grow closer as friends, and improve themselves in terms of in game ability, and in general skills such as coordination, co-operation and patience. (p. 7).

Of course, it is important to note that even the most advanced MMORPG's cannot offer a full sensory experience to their players (for example, the senses of smell and touch cannot be transmitted online), nor is it possible to experience the innumerable range of possible social situations and interactions online. Nevertheless, MMPORG's such as Second Life offer a more comprehensive amount of possible activities, such as going to restaurants, opening stores, driving and joining various clubs. As Bülow and Felix (2014) comment, "the more possibilities there are, the more possibilities individuals have to engage in shared activities in a wide range of areas." (p. 10) In this way, friendships that occur in the space of an immersive virtual world have an increased potential to eventually satisfy the Aristotelian criterion of shared activity as a necessary condition for friendship development. Additionally, research by Cole and Griffiths (2007) has showed that MMORPG's are in fact highly social games, with a high number of players reporting that they have made "life-long friends and even partners" (p. 582) through the game. These results could indicate that MMPORG's do have the potential to offer their players opportunities for robust friendships and very important intimate relationships.

It is remarkable to note that the philosophers who insist on the importance of the 'shared life' for the development of virtue friendship, do agree on the positive role the Internet can play in maintaining friendships that have started offline but due to various factors have to be largely conducted online. One might ask: why is there this divide in stance regarding using the Internet to maintain a (previously) offline friendship and a purely online one? A possible reply to this question could be that friendships that started offline but due to time and circumstance are now taking largely place online, have nevertheless been founded on spending time offline with our friend, sharing different activities and getting to really know their character. Since the goodness of our friend's character has been established in real life, it is not difficult for these friendships to be maintained online, if so needed. There could indeed be a distinction between simply maintaining and actually establishing a friendship through technological means. However, such an argument is again based on the presumption that physical proximity is a necessary condition for the development of virtue friendship.

Indeed, sharing experiences with our friends can deepen our bond and enhance our knowledge of their character. However, I would like to argue that spending time being physically together is not per se a necessary condition for the development of virtue friendships online. It is quite possible that deep and frequent exchanges of a personal nature online, with the two friends being open to honest self-disclosure about past events, present occurrences and future aspirations, coupled with shared activity online, (e.g. playing chess online, taking virtual museum tours together, listen to music together while sharing our emotional and aesthetic response to it) can still offset the lack of physical activities together in the offline world. Online friends can share their daily activities in great detail, from the mundane details of daily lunch to the special experience of becoming promoted or taking a rescue puppy home. They use technological media in order to make each other witness of important events, e.g. by making a webcam connection during a friend's graduation ceremony or birthday party. By participating in online activities together, and especially in activities with a strong element of play (such as online games), the two online friends can encounter many different situations and gauge each other's reactions to novel experiences.

This particular view of the shared life between friends is supported by philosophers who offer an alternative interpretation of the Aristotelian shared life argument. Liu (2010) in her analysis of the "living together with friends" Aristotelian point, argues that " Aristotle associates living together with conversing and sharing thoughts (...) he identifies it with sharing our favorite activities" (p. 593) In other words, one could sufficiently argue that the main characteristic of friends' shared lives is discussion and the sharing of thoughts. This point is further expanded to the online realm by Bülow and Felix (2014), who argue that "the idea that the most excellent activity friends can engage in is theoria, i.e., pure speculation. If one wants to, one can focus on doing theoria together when online." ( $p$. 11) They go on to point out that Aristotle was not too particular about where friends share their activities, as long as it gives them the feeling that they are living together in the way they themselves find most appropriate. The amount of activities that are possible online is constantly growing and offering for many robust opportunities for friends to spend time together. Their closing argument is, " seeing as it is possible to engage online even in theoria, the highest sense of human activity according to Aristotle, why should 
he not have accepted such an online relation as a perfect friendship? (p. 11).

Elder (2014) also makes a similar point: namely, that friends share life through discussion and rational thought. Wondering whether friends who love philosophy can discuss about it in social media and whether photography lovers can share and discuss each other's photographs online, she comes to the conclusion that this is indeed possible: "Sharing a conversation about one's day with a friend should count as living together, for Aristotelians, if we are to take his comments on the nature of the shared life seriously. Friends need not be present for every life event in order to share in a life: they needn't be grazing in the same field, like cattle". (p. 289) This is in reference to Aristotle's claim that sharing of discussion and thought is what sharing a life together means for men, "and not, as in the case of cattle, feeding in the same place" [NE IX.10: 1170b, 12-13] Finally, Wittkower (2012) in his analysis of communication and friendship on Facebook, he opines that Facebook actually is "a remarkably well-suited platform for the activity of friendship " (p. 25) due to the multitude of opportunities it offers for contact, communication, games and sharing between its members. These elements allow "the long-distance elements of friendship to become not a mere sharing of information about activities engaged in separately, but an active asynchronous sharing of activities themselves". (p. 25) We can thus conclude that, when it comes to the feasibility of sharing our lives with our online friends, the Internet with its various platforms and modes of communication can offer us viable alternatives for experiencing and sharing our lives with those we hold dear.

\section{'Settling' for less valuable forms of friendship online: arguments and counterarguments}

The third point of philosophers that view online friendship as a lesser form of friendship, namely, that pursuing such friendships online can be detrimental to our development as virtuous individuals, is one that deserves closer inspection and analysis. For the philosophers that uphold virtue friendship as the ideal form of friendship and maintain that virtue friendship is impossible to achieve online, the huge increase and development of online friendships can be seen as a disturbing trend. If people are "settling" for the lesser forms of friendship that are, according to these philosophers, indeed possible to achieve online (such as utility and pleasure friendship), then it is possible that they will not be motivated to make friendships of a higher value. As McFall (2012) states, "We may choose friendships as we please, but we should at least be aware of the highest form, lest we unknowingly mistake what we have for the highest" (p.
230). Similar warnings are given by Sharp (2012) who warns that pursuing friendship mostly or exclusively online, especially when using social networking sites, can lead to a more superficial kind of friendship. He makes the point that especially young people, who are still learning how to connect with others, seem to be taken by the many opportunities to create friendships online, citing a discussion with students where most of them believed they had close friends according to the Aristotelian definition. His analysis of this phenomenon is that we may "believe we have such friends, often because we conflate closeness with the sort of connection Aristotle has in mind. They are not the same, but even if they were, how would we find the time to get so close to one individual when we are monitoring the statuses and updates of so many people?" (p. 236). Sharp finds this a disturbing trend, especially since young people could mistake fleeting news updates with a true sense of friendship. His observations pertain to the nature and function of many social networking sites, on which one can have hundreds of friends whose lives one can follow by checking on their status updates; however, this is not conductive to building a virtue friendship, since such a friendship needs prolonged and intense interaction in order to build up trust and a sense of connection. He concludes his argument by stating, "If, as I believe, online friendships face significant obstacles in reaching the kind of consummate friendship that Aristotle discusses, and if the possibility of such a level of friendship is an important tool for realizing virtues, then our propensity to develop our friendships largely or solely online could be damaging our ability to develop as fully virtuous members of society" (p. 231).

Such assertions, although coming from a genuine place of concern, are still unnecessarily framing the issue in more simplistic terms. Online friendship becomes a cautionary tale, a hurdle to leading a virtuous life, an inferior replacement of tried and true friendship "in real life". Is online friendship really such a cause for concern? Let us provide a closer examination of such claims.

Continuing with Sharp, he states that "unfortunately, our ability to empathize with other people may already be diminishing from our increased tendency to communicate with other people more indirectly" (p. 237). As a defense of his argument, he offers research conducted by Konrath et al. (2011), which examined dispositional empathy on a sample of 72 American college students. The results showed that the ability for feeling empathic concern has dropped in the past decade. According to Sharp this is supposed to be due to the massive use of social media since this period. However, analyzing the original study presents us with a more complex view. The study is limited to only US nationals and only people of a certain age category, namely college students, making this not the most 
representative sample for a presumed reduction in empathy worldwide, as alluded by Sharp. Furthermore, this decrease in empathy is potentially attributed by Konrath et al. (2011) to different factors, including a rise of narcissism in young people, a societal focus and pressure for success, changes in media and technology and changing family practices. The link between the use of internet and social media and the reduction of empathy seems to be at best speculative, since the researchers only hypothesize between the rise of online media and changes in interpersonal dynamics: no concrete data that communicating with people online does reduce empathetic disposition is offered.

Poignantly, Sharp himself also acknowledges that internet use seems to be only one out of many possible factors responsible for this decline in empathy. However, he seems to not take into account that there has been empirical research examining the expression of empathy online, whose findings are not congruent with his claim that our empathetic abilities could be compromised from communicating with others online. For example, Preece and Ghozati (2001) have analyzed 100 different online communities and concluded that expression of empathy is common online, especially in communities where the focus is on patient support or emotional support. Such findings have been offered by other researchers as well, who report that especially in health communities, there is a very high level of emotional expression, empathy and understanding between the community members (Lamberg 2003; Siriaraya et al. 2011; Kaliarnta et al. 2011). Thus, empirical research does not seem to support the claim that online communication can inhibit our empathetic disposition.

Sharp's final point is that "the advent of Twitter and the desire for smaller, tighter status updates have led us to peruse the lives of others in brief snippets rather than seeking a deeper connection" (p. 238). However, this rather crude generalization seems to exclude the possibility that such short updates can still function as a way for people in our network to get to know more details about us, our daily life, our thoughts and ideas; thus, by knowing more information about us, they might choose to intensify their relationship with us. A recent study by Steijn and Schouten (2013) investigated the relationship between sharing personal information and relationship development in the context of social networking sites in the Netherlands. Their results indicated that sharing of personal information on social networking sites (SNSs) correlated strongly with a positive influence on our relationships with other members of one's network. More specifically, Steijn and Schouten found that on SNS's, relationships between friends and acquaintances (weak ties) were more likely to develop than relationship with close friends and family (strong ties) and that such a relationship development could be beneficial. They offered an explanation for this by arguing that due to lack of time and resources, maintaining many relationships through one-to-one contact is difficult and most of our news and information are shared with our closest friends and family members. When sharing our news publicly on an SNS, acquaintances and friends get more information than they normally would, which could make our relationship with these 'weak ties' more strong. As such, short updates on social networking sites can and do offer the possibility for a strengthening of ties between a user and his acquaintances or distant friends. Similar results were reported by Lange (2007) about a research conducted on creating, sharing and commenting of videos on YouTube videos. Lange found that "new media can function as a catalyst that helps facilitate social interaction at the local level. Specifically, it can strengthen weak ties and activate (...) social network ties that have the technical ability to interact but lie dormant prior to the introduction of new media into the social group." (pp. 1-2) Going back to Steijn and Schouten (2013), they also found that those who share more information on their profile report less frequently than others that there has been a decrease in relationship trust and intimacy. Steijn and Schouten opine that this may occur since the more information someone provides about himself, the more his online connections can form a complete picture of his likes and personality and thus avoid disappointment or incidents of misinterpretation. In other words, sharing more information about ourselves in social networks makes for more positive relationship development with our friends and acquaintances.

Similar points as those by Sharp (2012) are raised by Cocking et al. (2012): they wonder whether the limits and distortions of online interactions are now seeping in and negatively affecting offline relationships, especially when it comes to young people who have grown up making full use of the Internet: "if, like many teenagers today we increasingly grow up online, then we will be especially vulnerable to taking on or adapting to the conception, in this case of friendship, with which we are presented by our social environment" (p. 183). They offer the common example of teenagers having hundreds of friends on social media and they make the assertion that it is possible that many teenagers might actually believe that they have hundreds of 'true' friends, or alternatively, that teenagers constantly add new people on their online social network since it is seen as 'cool' to have so many friends and they would not want to appear left out.

It is true that the majority of young people and adolescents nowadays are very active online in various social networking sites and do have a great number of friends on these social media; however, this does not necessarily mean that teenagers assume that all the people in their online network are their friends. Boyd (2006) has 
conducted ethnographic research on social networking sites. Her data suggest that social network users tend to interpret the meaning of the word 'friend' (as used in a social networking site to denote someone you have added on your network) in a much broader sense. A 'friend' on a social networking site can be anything from a family member, a close friend, a colleague, a classmate, a neighbor, or someone you do not know yet-and social media users seem to be keenly aware of the distinction between all these categories, even when they are all lumped together under the moniker of 'friends'.

One thus must take care to not confuse 'Facebook friendships' (a large part of which are offline relationship which just get transferred into an online environment) with purely online friendships, where people have never met in real life. Various researchers which have conducted empirical studies on the use of social networking sites (Boyd 2014; Zinoviev and Duong 2009; Lampe et al. 2006; Lenhart and Madden 2007) have come to the conclusion that social networking sites are used primarily for strengthening relationships with offline friends and/or reestablishing connections with people from our pastmeeting new people online seems to be a secondary goal. Thus, one could argue that the example of friendships in social networking sites cannot be used to claim that online friendships in general are not as valuable, since in the majority of cases, friendships on social media are offline friendships with an online component, with purely online friendships (that is, friendships between people who have never met in real life) as a minority. At the very least, we can claim that this remains an open question.

Returning to the point about teenagers being especially sensitive to the possible degradation of the value of friendship due to social media, Boyd's work on the appropriation of the Internet and social media by teenagers offers some illuminating perspectives. Social media has taken the role that previously, real-life places like the mall or the neighborhood café had: they offer teenagers a place to "hang out" as it were-they act as a supplement of faceto-face interaction, not as a replacement. Additionally, due to the increasingly fast-paced lifestyles, social media afford teenagers with the opportunity to keep in touch with those they care about but due to time constraints cannot spend enough time physically. Boyd closes her book by opining that " networked publics are here to stay. Rather than resisting technology or fearing what might happen if youth embrace social media, adults should help youth develop the skills and perspective to productively navigate the complications brought about by living in networked publics." (p. 213). In a similar vein, Schols (2015) has conducted sociological research on the Internet use and social cohesion of adolescents in the Netherlands. She has concluded that 'adolescents' everyday Internet use does not inhibit their connectivity with others in their offline world, but instead promotes the relationships with their social ties and their social inclusion" (p. 158). Furthermore, Schols remarks that too much attention is given to the possible negative outcomes of teenage Internet use and calls for more research focused on the positive outcomes of teenager Internet use and how these positive outcomes can be brought about.

These empirical research results indicate that the effect of social media in the lives of teenagers might not be as negative as previously thought. Teenagers still spend time with friends, still try to make sense of themselves and their place in the world; the factor that has changed is that these activities now also take place online-however, without displacing the offline relationships teenagers have, but complimenting them in ways.

Regarding the issue of conflating online friendships with the 'higher' form of friendship, Fröding and Peterson (2012) take an even more radical stand by comparing online friendship with certain controversial forms of alternative medicine: just like an alternative medicine can end up poisoning instead of healing, so can a person's online friendships lead him to disillusionment and isolation instead of providing him with robust and meaningful companionship. They compare and contrast the connections one makes through an online professional networking site to the relationships formed through social networking sites. On professional networking sites, both parties have clear benefits from the relationship they develop and they are both aware that this is a professional relationship and not a friendship, thus professional networking sites do allow for mutually beneficial (albeit instrumental) relationships. On social networking sites however, some users might believe that by connecting to others through these sites, they are likely to gain genuine and meaningful friendships, when that is not always the case. They offer the constructed example of two women, Alice and Daniella, who are Facebook friends and communicate often. Alice spends a lot of time gardening and posting pictures of her garden online, and is very glad to receive Daniella's compliments about her beautiful garden. However, Daniella's sole purpose of befriending Alice is to get tips and tricks about gardening, so that she can tend better to her own garden. In this example, Alice is mistaken about the nature of her friendship with Daniella since she is not aware of Daniella's hidden agenda, so this online friendship not only has no moral value but it could also be harmful to Alice. So, for Peterson and Fröding, social networking sites cannot even meet the criteria for offering the 'lesser' forms of friendship. They claim that, unlike the users of business networking sites who have a clear understanding about the type and benefits of the relationships they develop, "the promise of the social network 
sites rings more hollow. Here the user is made to believe that she is likely to gain genuine friends and form meaningful and deep social relationships with other people" (p. 206).

However, their argument is problematic for two reasons: first, as we saw earlier, a large part of people who use online networking sites do so primarily in order to stay connected with friends they already know offline, and not so much for meeting new people online. This particular use seems to be supported by Facebook itself: in the Facebook 'Help' page, the question 'How to add friends on Facebook' is answered by offering two possibilities: searching for friends by typing their names or email addresses in the search bar, or by importing your e-mail contacts. ${ }^{3}$ In another page of the "Help" section, it is emphasized that Facebook users should only send friend requests to people they know personally. ${ }^{4}$ Also, empirical studies conducted show that only an estimated $30 \%$ of Facebook users add people they don't know as their friends, with the majority of users preferring to add family members, friends and acquaintances that they already know offline to their network of Facebook friends (Jones and Soltren, 2005). ${ }^{5}$ Thus, taking the above evidence into account, we can see that it is clear that at least in the case of one (and arguably, currently the biggest) social networking site, which is Facebook, the emphasis falls on connecting with already existing (close) friends and the users thus are not mislead. Secondly, the example Fröding and Peterson offer is rather poorly constructed and most definitely not limited to online friendships: relationships where one of the two parties has ulterior motives unbeknownst to the other person can also occur frequently offline. Yet, the possibility that we could be fooled does not stop us from connecting and creating friendships offline. As Elder (2014) observes, "If the potential for deception in real life is not sufficient to rule out the possibility of friendship, neither should it be considered especially hazardous to online friendship"'(p. 292). Similarly, Bülow and Felix (2014) point out that "all kinds of direct and indirect communication between people are potentially non-genuine. That is the risk one faces when involving oneself in relationships with other people, online or offline." (p. 8). In other words, although healthy caution should always be advised when entering a relationship, whether online or offline, the possibility of getting mislead online does not appear to be significantly higher than in offline settings.

\footnotetext{
3 https://www.facebook.com/help/146466588759199\#How-do-I-adda-friend?

${ }^{4}$ https://www.facebook.com/help/211926158839933\#Why-can't-Iadd-someone-as-a-friend?

${ }^{5}$ More empirical information confirming this has already been cited in pages $20-21$ of this article.
}

\section{Questioning the application of the Aristotelian framework on online friendships}

As such, it is clear that the arguments of the critics of online friendship can be rebutted: often the objections presented by the critics can be overturned with providing empirical evidence which points to the contrary. Many of the critics are actually implying various empirical claims without making this explicit, and offer no (or only partial or erroneously interpreted) empirical data. This concerns for example, Sharp's claims of reduced empathy online or the Fröding and Peterson claim that social networking sites can be as damaging as some kinds of alternative medicine. It is thus important that such claims are properly scrutinized and, where possible, empirical evidence should be presented as a way to support or counteract these claims. Of course, in the widely diverse selection of online environments and platforms, it is indeed possible that even empirical studies might not be in agreement with one another regarding the benefits or risks of online interactions. However, as Søraker (2012a) states, this only shows that such a question regarding online friendship is "immensely complex (...) [and] inherently context sensitive and different for each individual" (p. 213). Also, the different authors are unclear about defining the characteristics of online friendship and the means of communication between online friends are not fully specified. Are online friends completely anonymous or not? Are online friends those that have a friendship through e-mail? Or are they those who have a friendship through social networking sites or online games? Is the mode of interaction between online friends text-only or are voice and/or video online programs also used? Do they also have offline interaction or are they only discussing friendships that purely take place online? Without one clearly marked definition of online friendship, it could very well be that many of the philosophers are criticizing different things and their arguments possibly do not hold water for online friendships which do not fit their own particular definition.

However, a bigger point of contention is the rather narrow application of the Aristotelian framework on friendship by the critics of online friendship. One could argue that Aristotle's theory, while indeed being a benchmark theory regarding friendship and its importance on human flourishing, is nonetheless rather arbitrarily used in order to judge a a phenomenon (online friendships) that did not exist in the era Aristotle lived; No one could ever proclaim to know for sure that Aristotle, had he be living in our time, would be against the possibility of virtue friendships online. For example, the requirement for friends to spend physically time together was an absolute necessity in Aristotle's time, since two friends that were geographically apart could not engage in discussion with 
each other, nor could they experience new things together. Nowadays, this something that is possible, with the help of the internet and its various applications (Baym 2010; Boyd 2014; Bülow and Felix 2014; Elder 2014; Wittkower 2012).

More importantly, other philosophers such as Elder (2014) have used the Aristotelian theory of friendship in order to claim the opposite: that social media actually can facilitate the development of virtue friendships online. Elder argues that social media actually preserve important human values such as playfulness, exchange of ideas and reasoning. She then engages with six objections regarding the possibility of social media to offer places where friendships can flourish: these are objections regarding superficiality, privacy, physicality, deceptiveness, commercialism and poverty of communication. After refuting these objections, Elder concludes that "Rather than fear social media as a threat to genuine friendship, we should consider how it can be used to foster an important good, by considering it in the context of the shared life characteristic of the best friendships." (p. 292).

Elder's contribution to the debate regarding the possibility that virtue friendships can be realized online, signifies an important point: depending on its application, the Aristotelian framework can be used by some philosophers to claim that virtue friendships cannot be attained online, but other philosophers can apply it in a way that proves the opposite. In other words, one could make the argument that there is yet no definitive answer to the question whether online friendships can achieve the highest virtue level. If anything, this division of opinions could indicate that true virtue friendships are indeed possible to occur online, yet they are, just like in the offline world, rare. This possibility deserves closer examination, both philosophically and empirically.

Finally, it is worthwhile to again summarize some of the features that currently dominate the online landscape. The purely online friendships, where we had no direct connection to our friend's offline life, are beginning to fade. As long as we know our online friend's name, we can find their Facebook profile, their Twitter feed, we can add them on Skype so that we can see and hear each other. We can thus have a far more complete picture of who they are, even without ever meeting them. One then has to wonder how much weight the critics' argument about distorted presentation and lack of direct knowledge actually has under these circumstances. On the other hand, it is now commonplace to add our offline friends into our social media connections; this in turn blends our online and offline lives in a way that was uncommon in the early days of the internet. It would be useful if the critics could explain in more detail how this mingling of the online and the offline world could have deleterious effects, as they have previously suggested. Furthermore, the lack of "gating" features online has the effect that people connect with each other without having external factors like their age, gender, profession, race, disability etc. raise barriers between them and their friend. So it could be argued that these "limits" can actually promote the development of worthy friendships rather than hinder them.

More importantly, our increasingly mobile lifestyles present us with new friendship styles and opportunities. What about the people we meet briefly offline (say, at a conference or during holidays) and then connect and continue our contact online? We can argue that these relationships, even though they started in the offline world, are still extremely superficial, since the time and familiarity required for the development of friendship are absent in these cases. However, due to the possibility to deepen these relationship through contact via social media, emails or Skype, these connections could become deep and meaningful. Where would these friendships fall under? Are they online friendships, offline friendships that continue online (doubtful, given that due to the brevity of our offline contact, we could not speak yet of a friendship), or are they a new kind of hybrid relationship, the kind that could only exist and develop through the possibilities the Internet and social media offer? Wittkower (2012) also makes a valuable point about how Facebook can help resurrect friendships that have faded due to distance and time. All these opportunities for communication and friendship are afforded online, and it is important that we do not diminish their value.

Finally, even we were to concede to the online friendships critics that online friendships indeed are not virtue friendship 'proper', they still can be of invaluable worth for the people who have them. Søraker (2012b) mentions that there has been an "axiological turn" (p. 18) following the realization that technology often changes our lives radically without any direct right-or wrongdoing. As a way to better consider the multiple implications of technological change, he introduces the term "prudential", which "refers to something that is valuable for someone, contrasted with something that may be good in itself (if there is such a thing) or something that is good for something (which would typically be an instrumental value)"(p. 19). This is an important distinction because it moves away from the division between instrumental and intrinsic value by adding yet another dimension. I do believe and argue that online friendships can have great prudential value for the individuals involved. As Baym (2010) concludes, " These relationships make important contributions to people's lives [...] pairs who do become closer interact through multiple media, eventually making the influence of the internet difficult to conceptually distinguish from the many other influences on their partnership. [...] over time people 
can reveal themselves to one another verbally and nonverbally until they form understandings of one another as rich as, or richer than, those they hold of people they meet in any other way". (p. 131) Let us thus keep an open mind about the potential value and contribution of online friendships in our lives as virtual human beings.

\section{Conclusion}

In our current day and age, when large parts of human activity take place online, it is a natural consequence that people can and will connect with others on the Internet. In the everchanging landscape of the Internet, there are various communication platforms and methods that are continuously evolving and allowing us to have more information about our friends; we can use programs that actually allow us a far more interactive mode of communication with our online friends. Such connections can be very personal, deep and meaningful for the individuals concerned, providing companionship, a listening ear in times of need, intellectual discussion and stimulation. Dismissing such friendships as 'a lesser' kind by rigidly applying the Aristotelian theory of friendship to a mode of interaction and connection that was simply unthinkable in Aristotle's time is doing such friendships a disservice and tends to view technology's contribution to human connections and flourishing in a rather negative light. I propose that it is indeed necessary that greater attention should be paid to the positive sides and benefits of online friendships in a systematic way that takes into account the unique characteristics that online friendships have, and what could these kinds of friendships mean for our flourishing and well-being.

Open Access This article is distributed under the terms of the Creative Commons Attribution 4.0 International License (http://crea tivecommons.org/licenses/by/4.0/), which permits unrestricted use, distribution, and reproduction in any medium, provided you give appropriate credit to the original author(s) and the source, provide a link to the Creative Commons license, and indicate if changes were made.

\section{References}

Aristotle (2009) Nicomachean ethics (trans: Ross, W.D.). Oxford: Oxford University Press.

Bargh, J. A., McKenna, K. Y. A., \& Fitzsimons, G. M. (2002). Can you see the real me? Activation and expression of the "true self" on the internet. Journal of Social Issues, 58(1), 33-48.

Baym, N. K. (2010). Personal connections in the digital age. Cambridge, UK: Polity Press.

Bowden, P. (1997). Caring: Gender-sensitive ethics London. New York: Routledge.

Boyd, D. (2006). Friends, friendsters, and top 8: Writing community into being on social network sites. First Monday, 11(12). http:// firstmonday.org/article/view/1418/1336
Boyd, D. (2014). It's complicated: The social lives of networked teens. New Haven, London: Yale University Press.

Briggle, A. (2008). Real friends: How the internet can foster friendship. Ethics and Information Technology, 10(1), 71-79.

Bülow, W., \& Felix, C. (2014). On friendship between online equals. Philosophy and Technology. doi:10.1007/s13347-014-0183-6.

Butler, K. (2015) Girl posts photo on Facebook to find man she met on night out-But discovers he has a girlfriend. Manchester Evening News: Newspaper. Retrieved from http://www.manches tereveningnews.co.uk/news/greater-manchester-news/facebookpippa-mckinney-post-girlfriend-10199577. Accessed November 4, 2015.

Chan, D. K.-S., \& Cheng, G. H.-L. (2004). A comparison of offline and online friendship qualities at different stages of relationship development. Journal of Social and Personal Relationships, 21(3), 305-320.

Cocking, D. (2008). Plural selves and relational identity: Intimacy and privacy online. In J. Van den Hoven \& J. Weckert (Eds.), Information technology and moral philosophy (pp. 123-141). New York: Cambridge University Press.

Cocking, D., Van Den Hoven, J., \& Timmermans, J. (2012). Introduction: One thousand friends. Ethics and Information Technology, 14, 179-184.

Cole, H., \& Griffiths, M. K. (2007). Social interactions in massively multiplayer online role-playing gamers. CyberPsychology and Behaviour, 10(4), 575-583.

Elder, A. (2014). Excellent online friendships: An Aristotelian defense of social media. Ethics and Information Technology, 16, 287-297.

Fröding, B., \& Peterson, M. (2012). Why virtual friendship is no genuine friendship. Ethics and Information Technology, 14(3), 201-207.

Henderson, S., \& Gilding, M. (2004). 'I've never clicked this much with anyone in my life': Trust and hyperpersonal communication in online friendships. New media \& society, 6(4), 487-506.

How do I add a friend? Retrieved from, https://www.facebook.com/ help/146466588759199\#How-do-I-add-a-friend? Accessed March 28th, 2015.

Jones, H., \& Soltren, J. H. (2005). Facebook: Threats to privacy. December 14, 2005. Retrieved from http://groups.csail.mit.edu/ mac/classes/6.805/student-papers/fall05-papers/facebook.pdf. Accessed December 5th, 2013.

Kaliarnta, S., Nihlén Fahlquist, J., \& Roeser, S. (2011). Emotions and ethical considerations of women undergoing IVF-treatments. HEC Forum, 23(4), 281-293.

Konrath, S. H., O'Brien, E. H., \& Hsing, C. (2011). Changes in dispositional empathy in american college students over time: A meta-analysis. Personality and Social Psychology Review, 15, 180.

Lamberg, L. (2003). Online empathy for mood disorders. The Journal of the American Medical Association, 289(23), 3073-3077.

Lampe, C., Ellison, N., \& Steinfield, C. (2006). A Face (book) in the crowd: Social searching vs. social browsing. In Proceedings of CSCW-2006 (pp. 167-170). New York: ACM Press.

Lange, P. G. (2007) Fostering friendship through video production: How youth use YouTube to enrich local interaction. Paper presented at the International Communication Association Conference on May 27, 2007 in San Francisco, California. Retrieved from http://www.patriciaglange.org/page4/assets/ Lange \%20ICA\%202007\%20Paper.pdf. Accessed October 28th, 2015.

Lenhart, A., \& Madden, M. (2007, April 18). Teens, privacy, \& online social networks. Pew Internet and American Life Project Report. Retrieved from http://www.pewinternet.org/Reports/2007/ Teens-Privacy-and-Online-Social-Networks.aspx. Accessed December 5th, 2013. 
Liu, I. (2010). Love life: Aristotle on living together with friends. Inquiry: An Interdisciplinary Journal of Philosophy, 53(6), 579-601.

McFall, M. T. (2012). Real character-friends: Aristotelian friendship, living together, and technology. Ethics and Information Technology, 14, 221-230.

McKenna, K. Y. A., Green, A. S., \& Gleason, M. E. J. (2002). Relationship formation on the internet: What's the big attraction? Journal of Social Issues, 58(1), 9-31.

Munn, N. J. (2012). The reality of friendship within immersive virtual worlds. Ethics and Information Technology, 14, 1-10.

Preece, J., \& Ghozati, K. (2001). Observations and explorations of empathy online. In R. R. Rice \& J. E. Katz (Eds.), The internet and health communication: Experience and expectations (pp. 237-260). Thousand Oaks: Sage Publications Inc.

Schols, M. (2015) Young, online and connected. The impact of everyday Internet use of Dutch adolescents on social cohesion. Dissertation. EUR (189 pag.) Rotterdam: ERMeCC.

Sharp, R. (2012). The obstacles against reaching the highest level of Aristotelian friendship online. Ethics and Information Technology, 14, 231-239.

Siriaraya, P., Tang, C., Ang, C. S., Pfeil, U., \& Zaphiris, P. (2011). A comparison of empathic communication pattern for teenagers and older people in online support communities. Behaviour \& Information Technology, 30(5), 617-628.

Søraker, J. H. (2012a). How shall I compare thee? Comparing the prudential value of actual and virtual friendship. Ethics and Information Technology, 14, 209-219.

Søraker, J. H. (2012b). Prudential-empirical ethics of technology (PEET) - An early outline. APA Newsletter on Computing and Philosophy, 12(1), 18-22.

Steijn, W. M. P., \& Schouten, A. P. (2013). Information sharing and relationships on social networking sites. Cyberpsychology, Behavior and Social Networking, 16(8), 582-587.

Suler, J. (2004). The online disinhibition effect. CyberPsychology \& Behavior, 7(3), 321-326.

Turilli, M., Vaccaro, A., \& Taddeosaro, M. (2010). The case of online trust. Knowledge, Technology \& Policy, 23, 333-345.

Wittkower, D. E. (2012). Friend is a verb. APA Newsletter on Philosophy and Computers, 12(1), 22-26.

Why can't I add someone as a friend? Retrieved March 28th, 2015, from https://www.facebook.com/help/211926158839933\#Whycan't-I-add-someone-as-a-friend.

Zinoviev, D., \& Duong, V. (2009). Toward understanding friendship in online social networks. The International Journal of Technology, Knowledge and Society, 5(2), 1-8. 